\title{
Content Analysis of South African Sunday Newspaper Coverage of the Durban and Copenhagen Climate Change Conferences
}

\author{
Rendani Mulaudzi ${ }^{1} \&$ Joseph Kioko $^{1}$ \\ ${ }^{1}$ Faculty of Applied Sciences, Cape Peninsula University of Technology, Cape Town, South Africa \\ Correspondence: Rendani Mulaudzi, Faculty of Applied Sciences, Cape Peninsula University of Technology, Corner \\ Hanover and Tennant Street, Cape Town, 8000, South Africa.
}

Received: March 2, 2020

doi:10.11114/smc.v8i2.4749
Accepted: March 26, $2020 \quad$ Online Published: July 16, 2020

URL: https://doi.org/10.11114/smc.v8i2.4749

\begin{abstract}
Since the first United Nations climate change conference in 1995, newspapers have been vital in increasing coverage of climate change. Amidst growing number of events around climate change, the influence of international climate change conferences in newspaper coverage of climate change has not been fully interrogated in post-apartheid South Africa. This study aims to discover how three major South African Sunday broadsheet newspapers represented the Copenhagen conference (COP15) in 2009 and the Durban conference (COP17) in 2011. It used a national sample for the years 2009 and 2011, covering the City Press, The Sunday Independent and Sunday Times. The study carried out quantitative analysis of 58 articles published in the three leading Sunday newspapers between 01 January and 31 December. The direct involvement of South Africa on the Copenhagen and Durban climate change negotiations had an influence in the level of newspaper coverage. The frequency of articles published per month increased in November and December for all the years of interest. The dominantly reported main topics associated with COP are greenhouse gas emissions and the Kyoto Protocol. Both COP15 and COP17 were discussed frequently at a local level - domestic geographical scope. Overall, the article identified that South African print media is not consistent in the representation of COP. In order to better the reporting of international climate talks, print media has to be actively involved in integrative and collaborative engagement with $\mathrm{COP}$ relevant stakeholders.
\end{abstract}

Keywords: climate change, newspaper coverage, South Africa, Copenhagen conference, Durban conference

\section{Introduction}

After the first United Nations climate change conference in 1995, newspapers have been pivotal in increasing coverage of climate change. The climate change conference in Kyoto in 1997 is renowned for the adoption of the Kyoto Protocol. It was perceived as a legal force agreement to reduce atmospheric concentration of major greenhouse gases. This is particularly important in climate negotiations for one reason - the creation of mechanisms for emissions trading and emission reduction projects (Parker \& Karlsson, 2018). A number of studies demonstrated an increase in the coverage of climate change (Sampei \& Aoyagi-Usui, 2009). However, it is worth noting that few studies focus on the African continent. For example, most accounts of newspaper coverage of climate change, including focusing events, are in Australia, the UK and USA (Boykoff, 2012; Beeson \& McDonald, 2013; Schmidt, Ivanova, \& Schäfer, 2013).

Amidst growing knowledge of climate change, the Copenhagen conference in 2009 and the Durban conference in 2011 significantly marked an increase in obligations to reduce emissions by developed countries (Bäckstrand \& Lövbrand, 2019). As part of the international community, South African print media has been playing a key role in the global coverage of climate negotiations. For more than 12 years, it has been observed that the print media strongly referenced the Kyoto Protocol as the underlying influence of climate change coverage (Stoddart, Haluza-DeLay, \& Tindall, 2016). However, after 2009, the focus shifted to the coverage of a framework agreement, the Copenhagen Accord, established during the Copenhagen conference (León \& Erviti, 2011). The aim of the framework was to strengthen reduction targets by countries which constitute more than $80 \%$ of the global greenhouse gas emissions. Reduction targets were selected to be achieved by 2020 in comparison to the past emissions levels of 1990, 2000, and 2005, respectively (Groen \& Niemann, 2013; Falkner, 2016). Not long afterwards, in 2011, the Kyoto Protocol coverage was revitalized by the Durban conference. The conference agreed to adopt a roadmap, the Durban Platform for Enhanced Action, which attracted more attention from the media. Research clearly illustrates that how climate issues are represented in media is a vital factor, as is the 
quantity of representation (Kunelius, Eide, Tegelberg, \& Yagodin, 2017). Hackett, Forde, Foxwell-Norton \& Gunster (2017) recommended that media should play a leading role in the coverage of climate change response measures.

In the context of newspaper coverage of climate change, issue attention that recognizes the importance of climate negotiations is critically important. Increasing the exposure of climate change focusing events is a fundamental aspect with which to facilitate societal engagement on response measures. To enhance a holistic effective climate change coverage there is an urgent need to improve integrative approach in agenda-setting. The study aims to examine the representation of focusing events in the South African print media in 2009 and 2011.

\section{Previous Work and Framework}

There is strong evidence, based on the literature of media coverage of climate change, that the late 1980s was a turning point in an increase of newspaper attention to climate change (Boykoff \& Luedecke, 2016). The observation has been made that the focusing events on climate change can stimulate issue attention in news media (Schäfer, Ivanova, \& Schmidt, 2014; Eskjær, 2017).

While studies have shown a steady increase in issue attention to climate change after the publication of the Fourth Assessment Report of the Intergovernmental Panel on Climate Change (Fernández-Reyes, Piñuel-Raigada, \& VicenteMariño, 2015), print media coverage of high-level international climate change meetings was commonly at its peak during the course of the events. The Conference of Parties (COP) to the United Nations Framework Convention on Climate Change (UNFCCC), is the most important meeting for connecting science to policy in climate change. Studies continued to report the dynamics that influence the general trends in the coverage of COP events (Kumpu, 2016). Benford (2010) noted the potential importance of the involvement of non-governmental organizations has the ability to influence media attention.

Several accounts of the media attention have shown that the Copenhagen conference (COP15) was critical to the representations of climate change issue across many newspapers in the world - including The Australian in Australia, The Times in the UK, and The Washington Post in USA (Schmidt et al., 2013). Fundamental to the coverage of COP15 is the contribution of the three developed countries in the climate negotiations. Denmark, the hosting country of COP15, had a rise of climate talks news in the leading newspapers, including the Berlingske Tidende, and Politiken (Eskjær, 2017). The event contributed importantly to the coverage of climate change issue in other Scandinavian countries. For example, the Finnish newspaper, Helsingin Sanomat, recorded an increase in climate change stories in 2009 (Kumpu, 2016). African media coverage of climate change has been questionable during the COP15. There is clear evidence that only few South African newspapers such as Sunday Times and The Star, attempted to report news relating to climate change (Schmidt et al., 2013).

At the international level, the newspaper coverage of climate change declined during the Durban conference (COP17) in South Africa. In their work on reviewing newspaper coverage of climate change and global warming, Boykoff, Chandler, Nacu-Schmidt, \& Oonk (2020), noted that The Australian reported less stories in November and December 2011 (172 and 161 articles) compared to the same months in 2009 (562 and 683 articles). A similar outcome was reported by Wang, Nacu-Schmidt, McAllister, Giffored, Daly, Boykoff, Boehnert, \& Andrews (2014). The results show that COP15 had a limited coverage effect on the Australian newspapers. The same pattern has been exhibited in the UK, USA and Scandinavia. In Africa, South African newspapers were an important factor in the coverage of COP17. In general, the Business Day covered a considerable proportion of the stories during the event. The rise in coverage could be because South Africa was hosting the COP17 (Boykoff et al., 2020). There are examples of countries that have successfully increased the coverage during the focusing events, including France (Gurwitt, Malkki, \& Mitra, 2017).

Recent discussion on climate change communication has placed emphasis on the Issue-Attention Cycle conceptual model by Downs (1972). Central to a large proportion of studies is that the model is devoted to three set of prepositions: (1) public attention to an issue, (2) an issue towards issue-attention cycles, and (3) relationship between media attention, public attention, and governmental attention. As a basis for the model, the first preposition has five main stages - preproblem stage, alarmed discovery stage, cost of significant progress stage, decline of public interest stage, and the postproblem stage. What is interesting about the third preposition is not the fact that media plays a vital role in setting agenda (Sampei \& Aoyagi-Usui, 2009), but rather issue portrayal and public interest.

\section{Method}

A quantitative content analysis was employed with reference to the Copenhagen (COP15) and the Durban (COP17) conferences. The technique has been used by many similar studies on the topic of the media coverage of climate change (e.g. Krippendorff, 2013). For this study, relevant articles were identified using keyword searches (climate change or global warming; Copenhagen summit; Durban summit) in the SA Media database covering headlines and keywords. The search identified a total of 266 articles that dealt with United Nations climate change conferences, of which 58 articles 
were coded and analyzed. The search period selected was the years 2009 (01 January to 31 December) and 2011 (01 January and 31 December). In 2009 South Africa was amongst the first developing countries committed to implement selected targets to reduce greenhouse gas emissions in Copenhagen (Falkner, 2016).

Having noted that the Copenhagen Accord generated disagreements in relation to emissions reduction, the Durban summit attracted more attention. Media coverage was centered around a comprehensive guidance mechanism with clear lines of authority in the 21 st century. South Africa led the international community in the adoption of a roadmap, the Durban Platform for Enhanced Action. The roadmap was regarded as a tool to aid the establishment of a new legally binding protocol, and playing a vital role in the transition towards achieving emissions reduction targets beyond 2020 (Chan, Falkner, Goldberg, \& van Asselt, 2018; Parker \& Karlsson, 2018). Therefore, 2009 and 2011 were chosen because of the key role executed by South Africa during the focusing events.

The choice of City Press, The Sunday Independent, and Sunday Times is motivated by their national circulation. Although it is acknowledged that daily newspapers might have provided sufficient data, the three leading broadsheet newspapers are the only press media able to give a weekly summary of news genres, and thus produce the highest amount of science and policy issues. The sample was restricted to newspapers that are published in the English language. Like many studies dealing with climate change attention in the print media (e.g. Chand, 2017; Lidberg, 2018), quantitative content analysis was used to measure and analyze manifest content.

Table 1. Summary of the newspapers and articles in the sample

\begin{tabular}{lll}
\hline Newspaper & Total number of articles & $\%$ of total number of articles \\
\hline City Press & 16 & $28 \%$ \\
The Sunday Independent & 29 & $50 \%$ \\
Sunday Times & 13 & $22 \%$ \\
Total & 58 & $100 \%$ \\
\hline
\end{tabular}

\section{Results}

To understand the representation of international Conferences of the Parties (COP) to the United Nations Framework Convention on Climate Change in the print media, it is vital to look at their frequency of coverage and the main topics in the articles. Of the 58 articles, 29 (50\%) were published in The Sunday Independent, 16 (28\%) in the City Press and 13 $(22 \%)$ in the Sunday Times (Table 1).

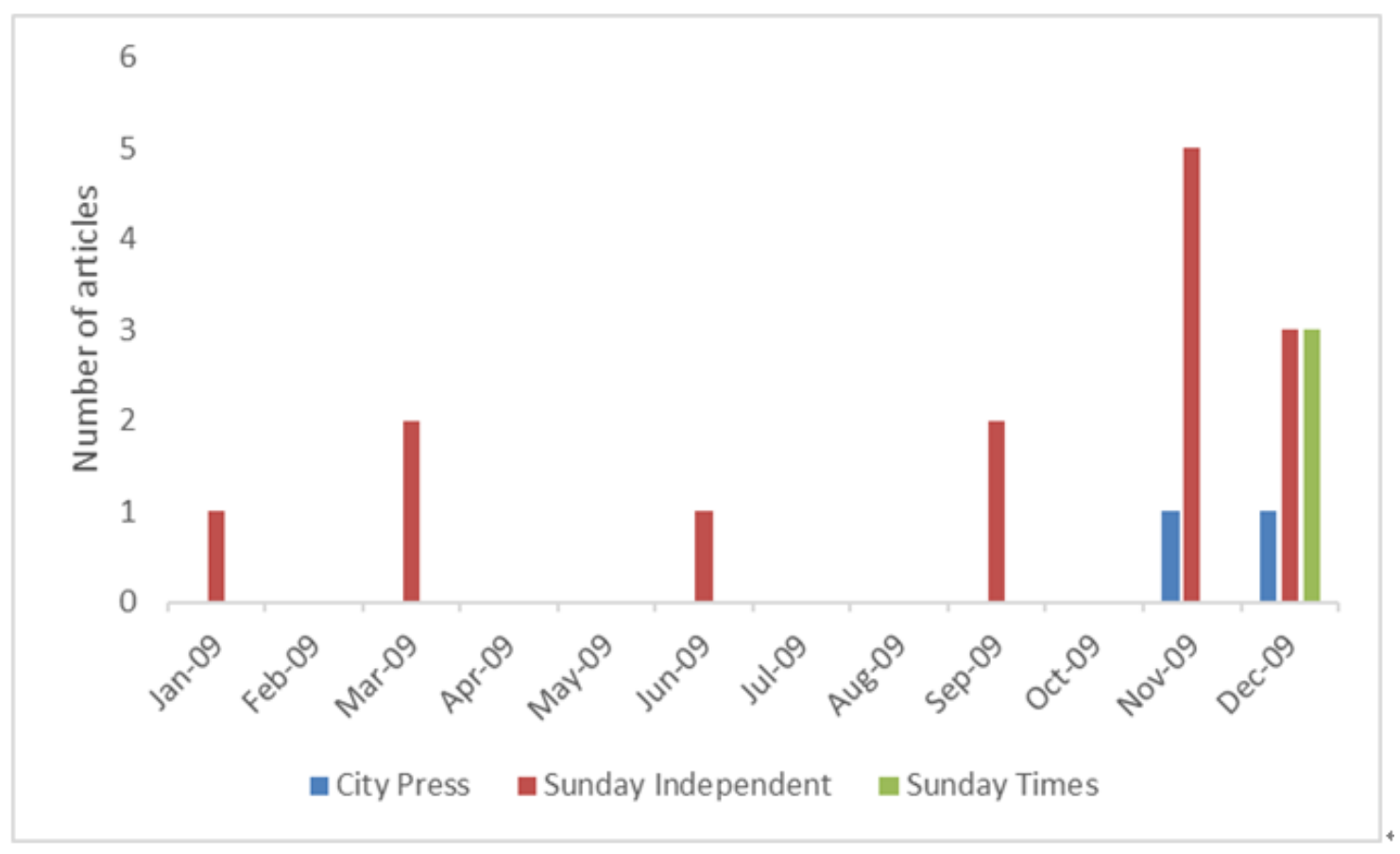

Figure 1. Frequency of the publication of articles about COP15 by months 


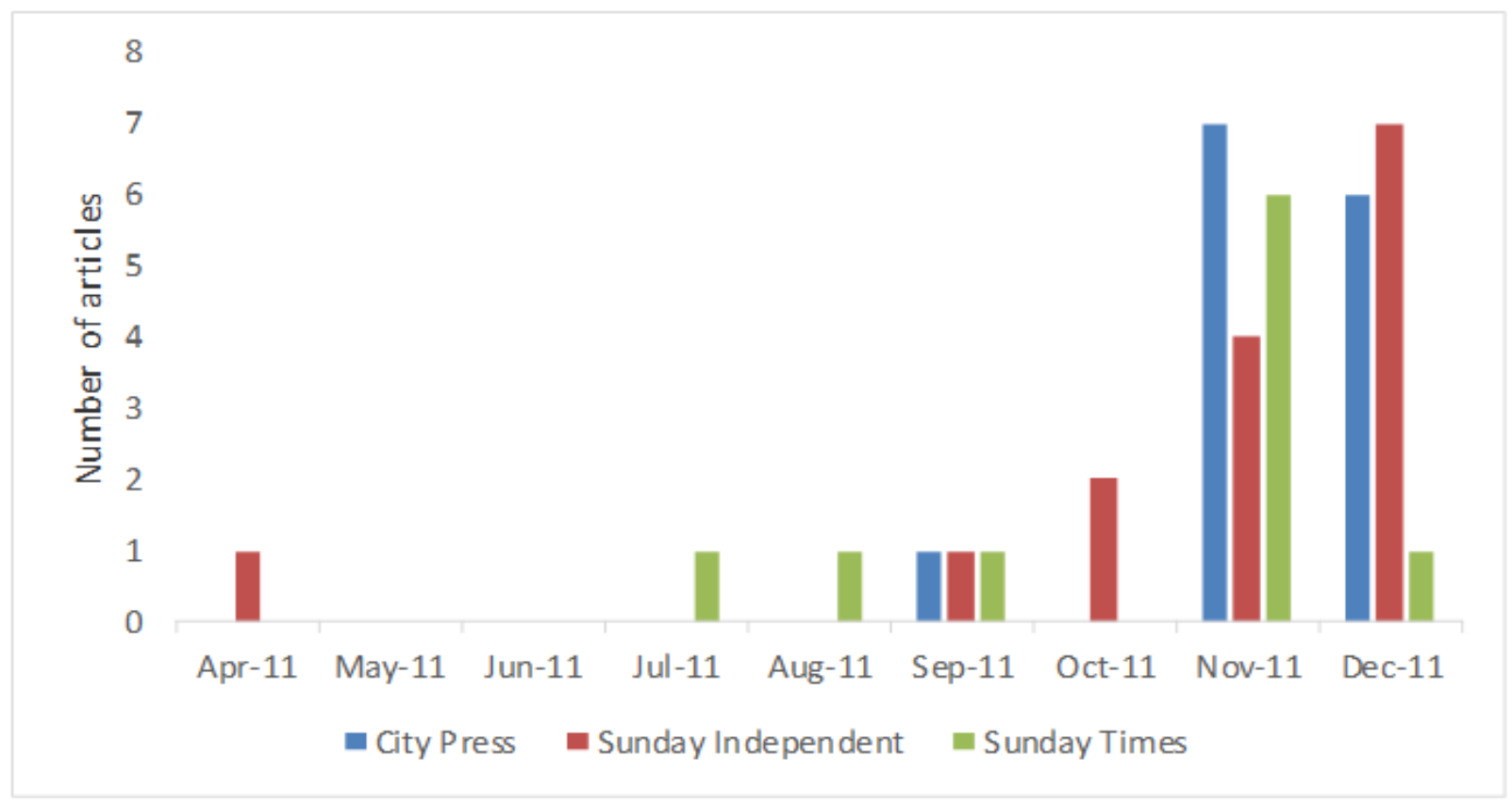

Figure 2. Frequency of the publication of articles about COP17 by months

The frequency of articles published per month increased in November and December for all the years of interest. The attention seems to be associated with the dates of the COP15 (07 to 18 December 2009) and COP17 (28 November to 09 December) events. For example, media coverage of COP research is generally characterized by massive event-based articles over the duration of the events (Chand, 2017; Lidberg, 2018). This echoed the findings of Eskjær (2017). Although there was a slight decline in COP coverage in December 2011, the overall number of articles covering COP17 (Figure 2) surpassed the average number of articles reporting on COP15 (Figure 1). These results raise a number of questions. Why did COP 15 receive less attention? Perhaps a more important question is why COP17 generated a great amount of coverage in the South African print media? To address the first question, it is thought no coincidence that the country was preparing for the 2010 FIFA world cup. The political climate in the country is likely to have been an influencing factor in agendasetting. For example, the national and provincial elections were held in 2009. Both figures 1 and 2 exhibit similarities with regard to the monthly coverage of COP events. Between January and June, COP15 and COP17 received little attention in the City Press and Sunday Times. The findings showed that no article was published by the above-mentioned newspapers during that period in 2009 and 2011. After a successful FIFA world cup, South Africa hosted thousands of delegates who attended COP17. The global and domestic media agencies shifted their attention to cover the climate talks in Durban.

The dominant reported main topics associated with COP are greenhouse gas emissions ( 31 articles) and the Kyoto Protocol (30 articles), which both significantly contributed to international climate negotiations. The representation of temperature in the City Press (1 article), is however far less than the reports in other newspapers (Table 2).

Table 2. Breakdown of main topics in which there was a dominant frame

\begin{tabular}{lllll} 
Newspaper & Kyoto Protocol & Greenhouse gas & Temperature & Other \\
\hline City Press & 7 & 7 & 1 & 5 \\
The Sunday & 19 & 13 & 5 & 4 \\
$\begin{array}{l}\text { Independent } \\
\text { Sunday Times }\end{array}$ & 4 & 11 & 4 & 1
\end{tabular}

Extreme weather events are other major topics also present but less frequently covered by the Sunday Times (1 article). An interesting result is that both COP15 and COP17 were frequently discussed at a local level ( 30 articles). This is reflected in the fact that domestic news was reported in 11 articles in 2009. The COP17 had the most attention, with 19 articles covering domestic news. Of the total of 39 articles, 13 were a mixture of both domestic and international news. 


\section{Discussion}

The representation of international climate talks in the print media was vital to inform the public on climate crisis issues. The coverage of COP went hand in hand with the improvements in the knowledge of climate change. It is accepted that the success of the media coverage of climate-related news is dependent upon issue attention and portrayal (e.g. Liu et al., 2008). The analysis identified that issue attention was associated with COP events. It is consistent with previous research about a clear trend towards increased media coverage during COP events (e.g. Chand, 2017). This can be illustrated through a large proportion of articles focusing on COP in the months of November and December. For example, COP17 was arguably a turning point for South Africa in climate negotiations (Banerjee, 2012). And in the print media, it was not surprising how the Durban Platform for Enhanced Action attracted attention, and Sunday newspapers were no exception. In fact, the attention is particularly noticeable because the Durban Platform for Enhanced Action failed to give an indication of the issues to be discussed on the international agenda. Most striking is the lack of an elaborated role of developed countries in addressing the challenges of climate change in the developing world (Bodansky, Brunnee, \& Rajamani, 2017). Despite limited coverage of COP15 by three leading Sunday newspapers, results nevertheless show similar monthly trends between COP15 and COP17.

Greenhouse gas emissions and the Kyoto Protocol were critical issues of interest in the coverage of COP15 and COP17. In the face of the changing climate systems, articles look back at the 1990s, to COP3 and the adoption of the Kyoto Protocol. Thus, when articles were represented by media, at least part of the explanation for reducing greenhouse gas emissions was based on the fundamentals of the Kyoto Protocol. The core principles of the Kyoto Protocol have been extensively documented (Grubb, Vrolijk, \& Brack, 2018). When some articles reported on the baseline information about greenhouse gas concentrations, they attempted to use human-induced activities as the main drivers. Over the early 2000s, deepening concern about increasing greenhouse gas emissions had a widespread impact on the establishment of the critically elaborated guiding principles for the Kyoto Protocol implementation. How then should we understand the focus of articles on the COP15? The starting point is the coverage of the negotiations to explore an integrated agreement to replace the Kyoto Protocol (Bodansky, 2010; Parker \& Karlsson, 2018). Much more important than the Copenhagen Accord was how the South African print media reported on the agreements of participants of the COP15 - they maintained it was possible to decrease global temperature to less than $2^{\circ} \mathrm{C}$.

Two years later, during the COP17, increasing global temperature and extreme weather events were given attention. Reporting on the climate change impacts and response measures was in line with the communication role played by the media.

When both COP15 and COP17 were reported on by articles in the City Press, The Sunday Independent and Sunday Times, the representations dwelled on domestic news relating to COP. However, there was a substantial variability between domestic and international news coverage in 2009. In contrast, in many existing literature sources (Eskjær, 2017), COP was at the center stage of international news coverage. The findings give an insight into the geographical scope of the coverage of two COP events, COP15 and COP17. The two were held within two years of each other. COP15 was overshadowed by the controversial period of the 2009 Climategate (Grundmann, 2013). And yet, results point out, that despite the scandal, the South African print media had a balanced coverage for COP15 at both domestic and international levels. Though COP17 was prioritized in domestic news, a further vital factor was that $33 \%$ of the articles portrayed the event in mixed geographical scope (domestic and international news). One possible reason could be the fact that South Africa was the hosting nation for the event.

\section{Conclusion}

In conclusion, the primary objective of this article was to give an insight into the representation of the United Nations climate change conferences by three leading Sunday newspapers in South Africa (City Press, The Sunday Independent and Sunday Times). The focusing events were the Copenhagen conference (COP15) in 2009 and the Durban conference (COP17) in 2011. The most important findings were that the frequency of COP coverage appreciated during the months of November and December. This is generally the period of the COP events. More importantly, results reveal that COP17 received more attention in the South African print media. This raised a fundamental question about the influence of the COP hosting nation regarding media coverage. In contrast, COP15 coverage could have been affected by the general elections and the preparation for the 2010 FIFA world cup.

While a majority of articles associated COP with factual and baseline information (i.e. greenhouse gas concentrations), extreme weather events were given little attention. Furthermore, the results revealed that domestic geographical scope was the main priority in the coverage of COP17. Overall, the article indicated that the South African print media is not consistent in the representation of COP events. This is also corroborated by the fact that some months had no COP news articles at all. In order to better report on international climate talks, the print media has to be actively involved in integrative and collaborative engagement with COP relevant stakeholders. This will improve communication in 
connecting science to policy in the realm of climate change. If we accept that the media is the main source of information, it is essential to provide accurate and detailed accounts of climate change focusing events.

\section{Acknowledgement}

The authors would like to thank Cyril JM Clarke for proofreading and editing.

\section{References}

Bäckstrand, K., \& Lövbrand, E. (2019). The road to Paris: Contending climate governance discourses in the postCopenhagen era. Journal of Environmental Policy and Planning, 21(5), 519-532. https://doi.org/10.1080/1523908X.2016.1150777

Banerjee, S. B. (2012). A climate for change? Critical reflections on the Durban United Nations climate change conference. Organization Studies, 33(12), 1761-1786. https://doi.org/10.1177/0170840612464609

Beeson, M., \& McDonald, M. (2013). The politics of climate change in Australia. Australian Journal of Politics and History, 59(3), 331-348. https://doi.org/10.1111/ajph.12019

Benford, R. D. (2010). Framing global governance from below: Discursive opportunities and challenges in the transnational social movement arena. In C. Bjola \& M. Kornprobst (Eds.), Arguing Global Governance (pp. 67-84). London \& New York: Routledge.

Bodansky, D. (2010). The art and craft of international environmental law. Massachusetts, London: Harvard University Press. https://doi.org/10.2139/ssrn.3000009

Bodansky, D., Brunnee, J., \& Rajamani, L. (2017). International climate change law. Oxford: Oxford University Press.

Boykoff, J. (2012). US media coverage of the Cancun climate change conference. PS: Political Science \& Politics, 45(2), 251-258. https://doi.org/10.1017/S104909651100206X

Boykoff, M., \& Luedecke, G. (2016). Elite news coverage of climate change. In Oxford Research Encyclopedia of Climate Science. Oxford: Oxford University Press. https://doi.org/10.1093/acrefore/9780190228620.013.357

Boykoff, M., Chandler, P., Nacu-Schmidt, A., \& Oonk, D. (2020). Australian Newspaper Coverage of Climate Change or Global Warming, 2000-2020. In Media and Climate Change Observatory Data Sets. Center for Science and Technology Policy Research, Cooperative Institute for Research in Environmental Sciences, University of Colorado.

Chan, S., Falkner, R., Goldberg, M., \& van Asselt, H. (2018). Effective and geographically balanced? An output-based assessment of non-state climate actions. Climate Policy, 18(1), 24-35. https://doi.org/10.1080/14693062.2016.1248343

Chand, S. (2017). Newspaper coverage of climate change in Fiji: A content analysis. Pacific Journalism Review, 23(1), 169-185. https://doi.org/10.24135/pjr.v23i1.310

Downs, A. (1972). Up and Down With Ecology-The "Issue-Attention Cycle". Public Interest, 28, 38-50.

Eskjær, M. F. (2017). Climate change communication in Denmark. In Oxford Research Encyclopedia of Climate Sciences. Oxford: Oxford University Press. https://doi.org/10.1093/acrefore/9780190228620.013.452

Falkner, R. (2016). The Paris Agreement and the new logic of international climate politics. International Affairs, 92(5), 1107-1125. https://doi.org/10.1111/1468-2346.12708

Fernández-Reyes, R., Piñuel Raigada, J. L., \& Vicente-Mariño, M. (2015). Journalistic coverage of climate change and global warming in El País, El Mundo and La Vanguardia. Latin Journal of Social Communication, 70, 122-140. https://doi.org/10.4185/RLCS-2015-1038en

Groen, L., \& Niemann, A. (2013). The European Union at the Copenhagen climate negotiations: A case of contested EU actorness and effectiveness. International Relations, 27(3), 308-324. https://doi.org/10.1177/0047117813497302

Grubb, M., Vrolijk, C., \& Brack, D. (2018). Routledge Revivals: Kyoto Protocol (1999): A Guide and Assessment. Abingdon: Routledge. https://doi.org/10.4324/9781315147024

Grundmann, R. (2013). Climategate and the scientific ethos. Science, Technology \& Human Values, 38(1), 67-93. https://doi.org/10.1177/0162243911432318

Gurwitt, S., Malkki, K., \& Mitra, M. (2017). Global issue, developed country bias: the Paris climate conference as covered by daily print news organizations in 13 nations. Climatic Change, 143(3-4), 281-296. https://doi.org/10.1007/s10584-017-2004-2

Hackett, R., Forde, S., Foxwell-Norton, K., \& Gunster, S. (2017). Journalism and climate crisis: Public engagement, media alternatives. New York: Routledge. https://doi.org/10.4324/9781315668734 
Krippendorff, K. (2013). Content analysis: An introduction to its methodology ( $3^{\text {rd }}$ ed.). Los Angeles: SAGE Publications.

Kumpu, V. (2016). On making a big deal. Consensus and disagreement in the newspaper coverage of UN climate summits. Critical Discourse Studies, 13(2), 143-157. https://doi.org/10.1080/17405904.2015.1042392

Kunelius, R., Eide, E., Tegelberg, M., \& Yagodin, D. (2017). Media and global climate knowledge. New York: Palgrave Macmillan. https://doi.org/10.1057/978-1-137-52321-1

León, B., \& Erviti, M. C. (2011). Portrayal of scientific controversy on climate change. A study of the coverage of the Copenhagen summit in the Spanish press. Observatorio $\left(O B S^{*}\right), 5(3), 45-63$.

Lidberg, J. (2018). Australian media coverage of two pivotal climate change summits: A comparative study between COP15 and COP21. Pacific Journalism Review: Te Koakoa, 24(1), 70-86. https://doi.org/10.24135/pjr.v24i1.405

Liu, X., Vedlitz, A., \& Alston, L. (2008). Regional news portrayals of global warming and climate change. Environmental Science and Policy, 11(5), 379-393. https://doi.org/10.1016/j.envsci.2008.01.002

Parker, C. F., \& Karlsson, C. (2018). The UN climate change negotiations and the role of the United States: assessing American leadership from Copenhagen to Paris. Environmental Politics, 27(3), 519-540. https://doi.org/10.1080/09644016.2018.1442388

Sampei, Y., \& Aoyagi-Usui, M. (2009). Mass-media coverage, its influence on public awareness of climate change issues, and implications for Japan's national campaign to reduce greenhouse gas emissions. Global Environmental Change, 19, 203-212. https://doi.org/10.1016/j.gloenvcha.2008.10.005

Schäfer, M. S., Ivanova, A., \& Schmidt, A. (2014). What drives media attention for climate change? Explaining issue attention in Australian, German and Indian print media from 1996 to 2010. International Communication Gazette, 76(2), 152-176. https://doi.org/10.1177/1748048513504169

Schmidt, A., Ivanova, A., \& Schäfer, M.S. (2013). Media attention for climate change around the world: A comparative analysis of newspaper coverage in 27 countries. Global Environmental Change, 23(5), 1233-1248. https://doi.org/10.1016/j.gloenvcha.2013.07.020

Stoddart, M. C., Haluza-DeLay, R., \& Tindall, D. B. (2016). Canadian news media coverage of climate change: Historical trajectories, dominant frames, and international comparisons. Society and Natural Resources, 29(2), 218-232. https://doi.org/10.1080/08941920.2015.1054569

Wang, X., Nacu-Schmidt, A., McAllister, L., Giffored, L., Daly, M., Boykoff, M., \& Andrews, K. (2014). World Newspaper Coverage of Climate Change or Global Warming, 2004-2014. In Center for Science and Technology Policy Research, Cooperative Institute for Research in Environmental Sciences, Retrieved March 20, 2020, from $\mathrm{http}: / /$ sciencepolicy. colorado.edu/media_coverage.

\section{Copyrights}

Copyright for this article is retained by the author(s), with first publication rights granted to the journal.

This is an open-access article distributed under the terms and conditions of the Creative Commons Attribution license which permits unrestricted use, distribution, and reproduction in any medium, provided the original work is properly cited. 